\title{
TENSILE AND FLEXURAL BEHAVIOUR OF GRAPHITE FILLER PARTICLES AND PINEAPPLE LEAF FIBER (PALF) REINFORCED POL YMER COMPOSITES
}

\author{
Mahadeva Reddy ${ }^{l *}$, B Adaveesh ${ }^{l}$, Mohan Kumar $T S^{l}$, Madeva Nagaral ${ }^{2}$ \\ ${ }^{1}$ Department of Industrial Engineering and Management, Siddaganga Institute of \\ Technology, Tumakuru-572103, Karnataka, India \\ ${ }^{2}$ Deputy Manager, Aircraft Research and Design Centre, Hindustan Aeronautics \\ Limited, Bangalore-560037, Karnataka, India
}

Received 12.06.2021

Accepted 09.09.2021

\begin{abstract}
New composites materials are developed to meet the demand for medical devices, vehicles, protective equipment, sporting goods, etc. In present investigations, the effects of graphite filler particles in the epoxy were studied separately by preparing epoxy with 5 and 10 vol.\% of graphite filler particles composites by hand layup technique. Further, the combined effect of graphite filler particles and pineapple leaf fibers (PALF) on the mechanical behaviour of epoxy composites was studied by preparing epoxy with 5 vol.\% of graphite -30 vol.\% of PALF and epoxy with 10 vol.\% of graphite -30 vol.\% of PALF composites. Prepared composites were subjected to evaluating various mechanical properties like tensile strength, elongation, and flexural strength as per ASTM standards. By adding graphite filler particles and PALF fibers tensile, and flexural strength were improved with a slight reduction in the percentage elongation. Further, these conventional results were validated by FEM analysis using MSC Patran and Nastran Student Version.
\end{abstract}

Keywords: graphite filler particles; pineapple leaf fibers; polymer composites; mechanical properties; flexural strength; FEM analysis. 


\section{Introduction}

Generally, any material containing two or more constituents with dissimilar properties and distinct boundaries between the constituents can be referred to as a composite material. Moreover, the idea of joining several components to create a material with possessions that are not attainable with the individual components has been used by man for thousands of years. Correspondingly, most natural constituents that have emerged as a result of the prolonged evolution process can be treated as composite materials [1].

The demands for advanced materials with improved properties have been increasing. This expansion has significantly contributed to the advent of new polymermatrix composite material, so that facilitate improvement of properties of a material that could use in various engineering applications, including automobile, aircraft and structural composites, biomedical \& sporting materials etc. The high performance of continuous synthetic fiber reinforced polymer matrix composite is thoroughly known and documented; however, synthetic fibers and polymers that come from traditional sources of energy per year more than 140 million tons of crafted from synthetic polymers [2]. This fiber reinforced plastic (FRP) is used in a variety of applications from a household kitchen to aerospace, but once used, it is unable to be reused, so disposal problems are challenging, FRP being a non-degradable material [3]. Pineapple is a non-climacteric and the third most commonly grown after bananas and citrus [4]. Alfredo et al. [5] studied the impact of 12 different varieties of pineapple fibres on the technological, chemical, structural and morphological properties of polymer composites. Mechanical properties and chemical behaviour of polymer composites were improved by adding pineapple fibers.

Moreover, the natural fiber extracted from leaves, among other the PALF has the highest $\%$ of cellulose content with a low microfibrillar angle. This is the principal responsible factor for improving tensile properties. So, choosing PALF reinforced fiber in polymer composite is due to many reasons such as cheaper, excellent tensile strength, high toughness, and good thermal and acoustic insulation \& abundantly available in nature. The type of matrix used influences the mechanical properties of the composite, and the durability of the composite is also affected. The thermoplastic and the thermosetting polymer is the most common type of matrix resin used in polymer composites. Many scholars have assessed the PALF reinforced thermoset composites such as polyester \& epoxy polymers c for mechanical properties [6-8]. On assessing all resins, thermoset-based resin conveyed superior mechanical properties to thermoplastics and bio-gradable resins. So, epoxy polymers have excellent properties, including good thermal and mechanical properties, compatible with any type of fiber with low cost [9]. Because of these properties, it makes them more suitable for use in wide-ranging applications such as adhesive coatings structural materials or as the composite matrix [10, 11]. Sathees Kumar et al. [12,13] investigated the effect of graphite and silicon carbide fillers on the mechanical properties of PA6 polymer composites.

Epoxy has a higher degree of crosslinking, so it will enhance the rigidity and strength of the material. However, because crosslink epoxy becomes more brittle and vulnerable to break, due to this problem of epoxy, many researchers have worked on how to improve the epoxy toughness by adding filler into the polymer. The mechanical and tribological properties would maintain adequately because of the filler and less resin material consumption, so direct cost reduction is possible [14-16]. In the current 
research, expandable graphite is used due to its remarkable effect on the polymer properties at low filler fractions, polymer/ graphite-based nanocomposite has attracted most academics and industry in recent years [17-19]. The polymer contains layered structure molecule, so layer by layer structured graphite have the capability to improve mechanical toughness due to its excellent properties [20,21]. Tensile modulus of epoxy would increase due to an increase in graphite filler content [22-24]. Tensile properties of polymer composites have been improved due to a strong interface between the fiber and matrix with uniform distribution of graphite filler particles.

In this study, an experimental study was carried out to characterise the mechanical properties of graphite filler particles and pineapple leaf (PALF) fibers reinforced epoxy composites. The aim of this work was to study the effect of 5 and 10 vol.\% of graphite filler contents and $30 \mathrm{vol} . \%$ of pineapple leaf fibers on ultimate strength, yield strength, elongation and flexural strength of polymer composites.

\section{Experimental Details}

\section{Materials}

Epoxy has been the major matrix material of polymer matrix composites for aerospace and automotive applications for many years. This is attributable to ease of processing, good mechanical properties, and low cost. Hence, in the present study epoxy matrix material was prepared at room temperature by mixing epoxy LY 556 and hardener HY 951 as in Fig. 1 (a) in a 10:1 ratio as per supplier instruction.

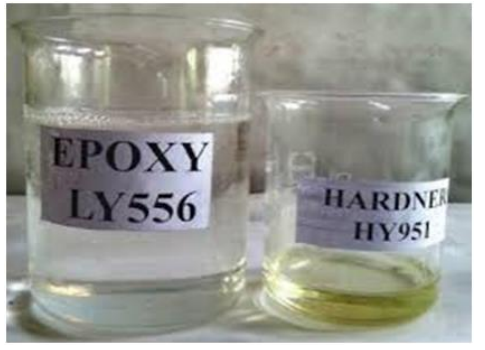

a)

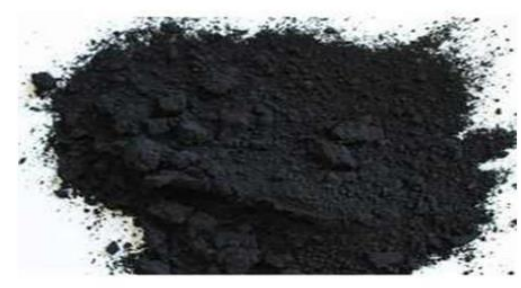

b)

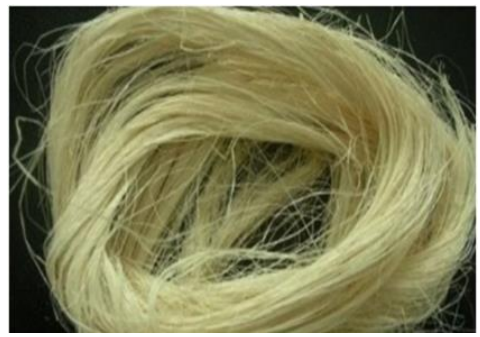

c)

Fig. 1 (a) Epoxy and hardener (b) expanded graphite filler particles (c) Pineapple leaf fibers. 
Expanded graphite particles were used as a filler material to prepare the epoxy polymer composites, $10 \mathrm{~nm}$ size expanded graphite particles used in the current investigations as shown in Fig. 1 (b) procured from Ultrananotech Private Limited, Bangalore. Pineapple leaf fibers (PALF) were used as the major reinforcement material to prepare the hybrid polymer composites. Epoxy with 5\% of graphite filler and $30 \%$ of PALF and one more set of hybrid composites of epoxy with $10 \%$ of graphite filler and $30 \%$ of PALF. Pineapple leaf fibers with $91 \mathrm{~nm}$ in diameter and $300 \mathrm{~mm}$ in length used to prepare the epoxy composites are shown in Fig. 1(c) were procured from Go Green Products Guntur, Andrapradesh.

\section{Preparation of Polymer Composites and Testing}

The hand layup process was adopted to prepare the epoxy with graphite fillers and PALF fibers reinforced composites. Initially, in the 10:1 ratio, LY 556 epoxy and HY 951 hardener mixer were prepared. Further, in this prepared mixer of epoxy 5\% (volume) of graphite filler particles were dispersed thoroughly by a manually operated mechanical stirrer. A mould of $300 \times 300 \mathrm{~mm}$ with $4 \mathrm{~mm}$ thickness was utilised to synthesize the final composites (Fig. 2). The epoxy with 5 vol.\% of graphite filler composite was poured into the mould to get the graphite filler particles reinforced polymer composites.

Further, $10 \%$ of graphite particles reinforced polymer composites were obtained by the same procedure. $30 \mathrm{vol} \%$ of pineapple leaf fibers were used in the mould by layup process, and 5 vol.\% of graphite filler reinforced epoxy to synthesize hybrid composite. Finally, 300 x $300 \mathrm{~mm}$ flat plate with a $4 \mathrm{~mm}$ thick composite plate was obtained after 6 hours of curing, as in Fig. 3. Similarly, one more set of hybrid composites were fabricated by varying the volume percentage of graphite fillers. Table 1 represents the various composites prepared in the current study.

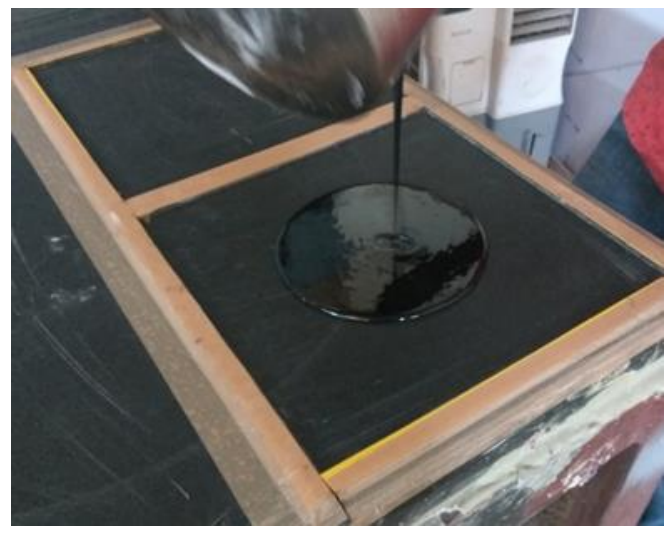

Fig. 2. Preparing the mould with dimensions $300 \times 300 \times 4 \mathrm{~mm}$. 


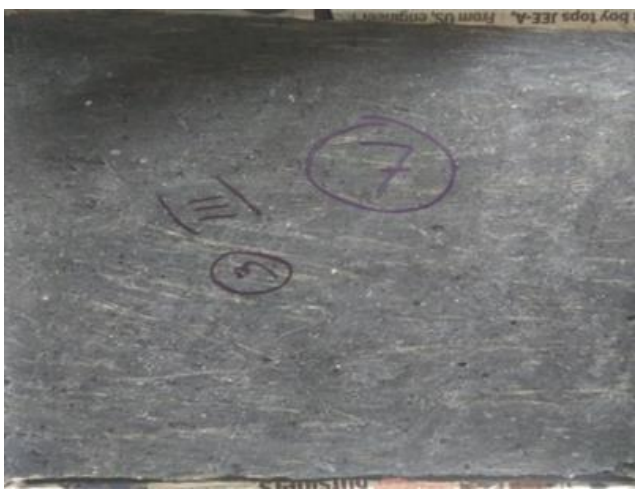

Fig. 3. Epoxy with graphite filler and PALF composites.

Table 1. Prepared composites composition.

\begin{tabular}{ccccc}
\hline Composition & $\begin{array}{c}\text { Composite } \\
\text { Code }\end{array}$ & $\begin{array}{c}\text { Epoxy } \\
(\text { Vol. } \%)\end{array}$ & $\begin{array}{c}\text { Graphite } \\
(\text { Vol. } \%)\end{array}$ & $\begin{array}{c}\text { PALF } \\
(\text { Vol. } \%)\end{array}$ \\
\hline Epoxy-5\% Graphite & A & 95 & 5 & - \\
Epoxy-10\% Graphite & B & 90 & 10 & - \\
Epoxy-5\% Graphite- & C & 65 & 5 & 30 \\
30\%PALF & & & 10 & 30 \\
Epoxy-10\% Graphite- & D & 60 & & \\
$30 \%$ PALF & & & & \\
\hline
\end{tabular}

Table 2 shows the various physical and mechanical properties of epoxy, graphite, and PALF fibers.

Table 2 Physical and Mechanical Properties of epoxy, graphite and Pineapple Leaf Fibers [25].

\begin{tabular}{cccc}
\hline Properties & Epoxy & Graphite & Pineapple Leaf Fibers \\
\hline Density $\left(\mathrm{g} / \mathrm{cm}^{3}\right)$ & 1.1 & 2.20 & 1.52 \\
Strength $(\mathrm{MPa})$ & 55 & 70 & $413-1627$ \\
Modulus $(\mathrm{GPa})$ & 1.75 & $10-15$ & $34.5-82.81$ \\
Cellulose $(\%)$ & -- & --- & $74.33-85$ \\
\hline
\end{tabular}

These prepared composites were machined as per ASTM standards to study the various mechanical properties. Fabricated epoxy with 5\% graphite (A), $10 \%$ graphite (B), 5\% graphite-30\% PALF (C) and 10\% graphite-30\% PALF(D) composites of 
dimensions $250 \mathrm{~mm} \times 25 \mathrm{~mm} \times 4 \mathrm{~mm}$ were subjected to tensile tests as per ASTM D3039 standard [26]. From the experimentation, tensile properties such as tensile strength and elongation were found. For all the compositions average value of 3 specimens was reported.

Influences of graphite filler particles and PALF on the flexural properties of epoxy composites were investigated. Fabricated epoxy composites with $5 \%$ graphite, $10 \%$ graphite, $5 \%$ graphite-30\%PALF and $10 \%$ graphite-30\% PALF composites of dimensions $127 \mathrm{~mm} \times 12.7 \mathrm{~mm} \times 4 \mathrm{~mm}$ were subjected to flexural tests as per ASTM D790 standard [27]. For each composition, three specimens were tested, and the average value was reported. Further, these tensile and flexural tests conventional results were validated by FEM analysis using MSC Patran and Nastran Student Version.

\section{Results and Discussion}

Tensile Properties

Table 3. Tensile properties of epoxy with graphite and PALF composites.

\begin{tabular}{ccc}
\hline Composite Code & Tensile Strength (MPa) UTM & Tensile Strength (MPa) FEM \\
\hline A & 42.53 & 43.4 \\
B & 43.80 & 44.7 \\
C & 45.37 & 46.25 \\
D & 47.68 & 48.12 \\
\hline
\end{tabular}

Table 3 and Fig. 4 demonstrate the tensile strength of epoxy with 5\% of graphite, $10 \%$ of graphite, $5 \%$ graphite, and $30 \%$ PALF and $10 \%$ graphite, and $30 \%$ PALF reinforced composites. The prepared varying volume percentage of graphite and PALF fibers reinforced composites coded by A, B, C, and D as shown in Tables 1 and 2 accompanied by Fig. 2. The tensile strength of 5\% graphite fillers reinforced epoxy composite is $42.53 \mathrm{MPa}$. Further increase in the content of graphite fillers to $10 \%$ in the epoxy strength has enhanced to $43.80 \mathrm{MPa}$. Tensile strength of epoxy enhanced with the addition of varying volume fractions of graphite fillers. Further, the incorporation of $30 \%$ of pineapple leaf fibers along with 5\% graphite fillers showed an improved tensile strength of $45.37 \mathrm{MPa}$. In the case of $10 \%$ graphite fillers and 30\% PALF reinforced epoxy composites, it is $47.68 \mathrm{MPa}$. 


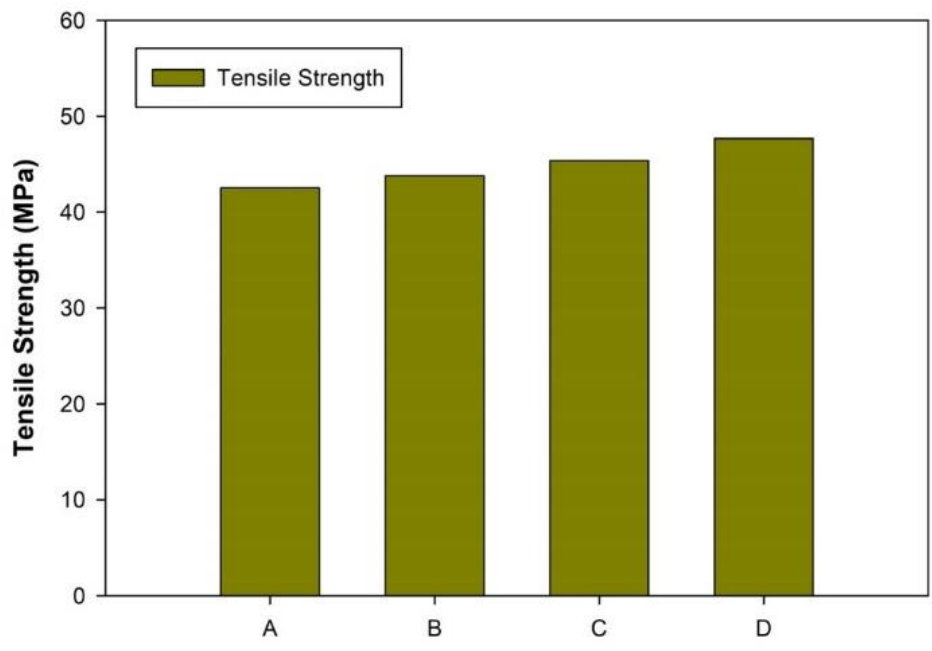

Graphite Fillers and PALF Reinforced Epoxy Composites

Fig. 4. Tensile strength of graphite fillers and PALF reinforced epoxy composites.

The highest tensile strength is observed with the increasing content of graphite fillers, along with $30 \%$ of pineapple fibers reinforced composites. The enhancement of tensile strength is due to the presence of graphite particles in all directions in the epoxy. Further, the presence of PALF improved the strength, which carries the major axial load during the tensile test. Temesgen et al. [28] was noted a similar kind of enhancement in the mechanical behaviour of banana and glass fibers reinforced epoxy composites.

Further, conventional tensile test results are validated using FEM analysis using MSC Patran and Nastran student version software. Fig. 5 shows the tensile model created for analysis with the same dimensions used in the conventional tensile testing i.e.,

$250 \mathrm{~mm} \times 25 \mathrm{~mm} \times 4 \mathrm{~mm}$ with 310 nodes and 250 shell elements.

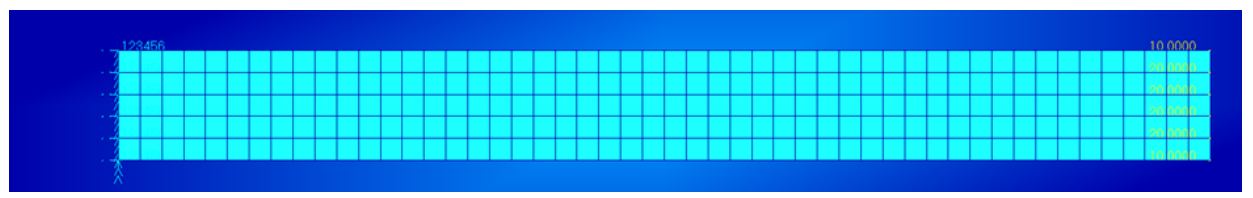

Fig. 5.Tensile model for FEM analysis

Fig. 6 (a-d) demonstrates the tensile strength of varying volume fractions of graphite fillers and 30\% PALF reinforced epoxy composites determined by the analysis method. The tensile strength of $5 \%$ graphite fillers reinforced epoxy composites obtained from the FEM method is $43.4 \mathrm{MPa}$, as Fig. 6(a). Similarly, for 10\% graphite fillers reinforced composites, the tensile strength is $44.7 \mathrm{MPa}$ (Fig. 6b), in the case of $5 \%$ graphite-30\% PALF and 10\% graphite-30\% PALF composites, it is $46.2 \mathrm{MPa}$ and 48.1 MPa, respectively, as shown in Fig. 6(c-d). The conventional tensile strength results as in Fig. 4 are in line with FEM analysis results. 


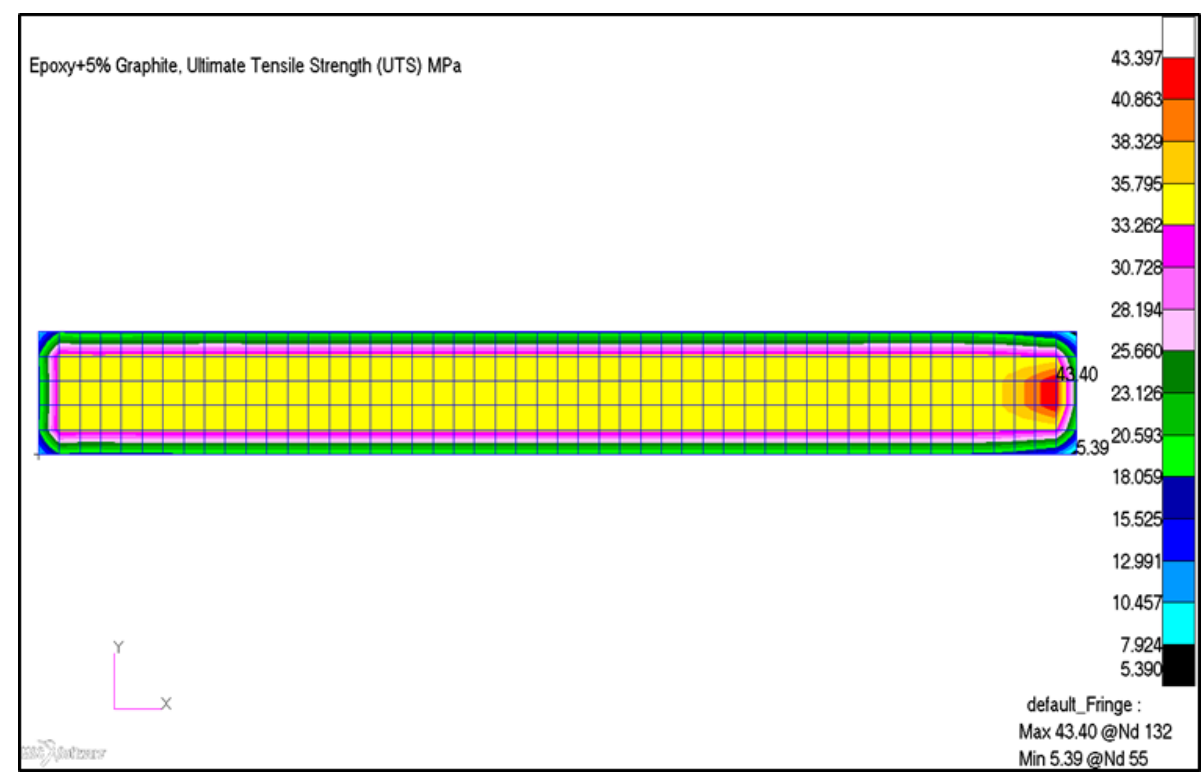

a)

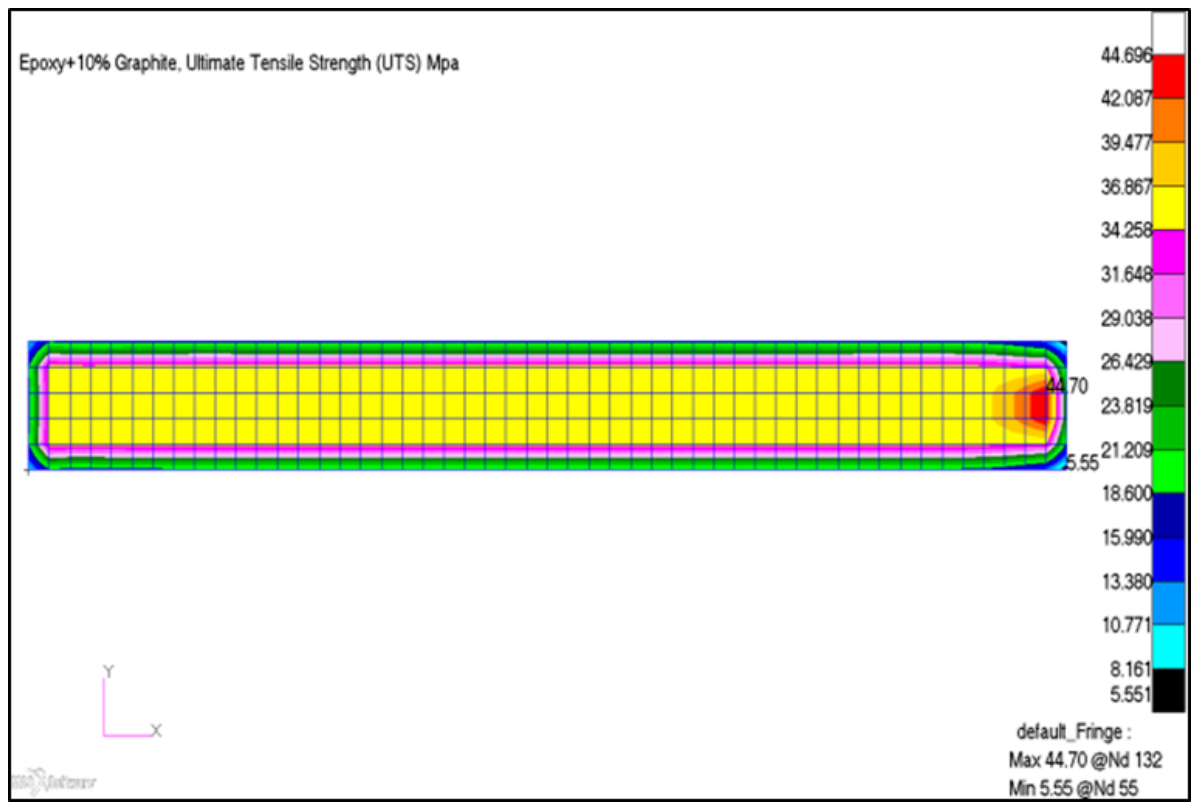

b) 


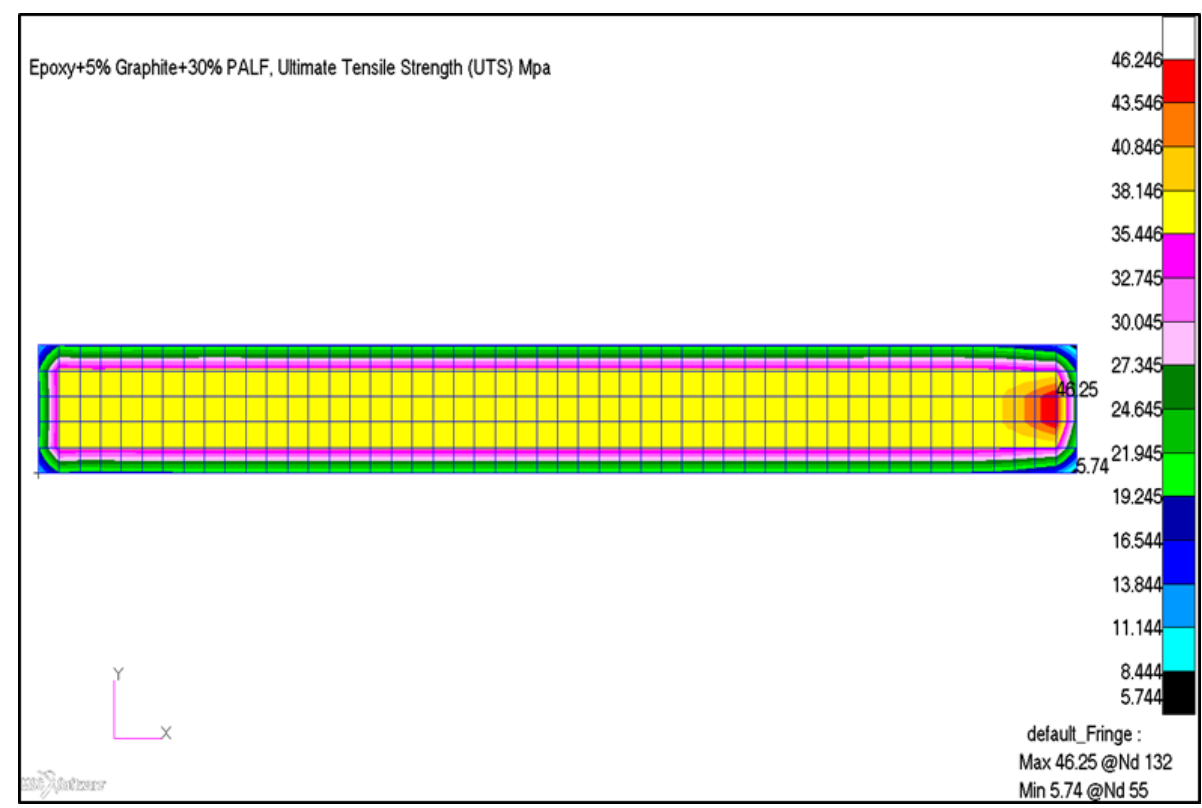

c)

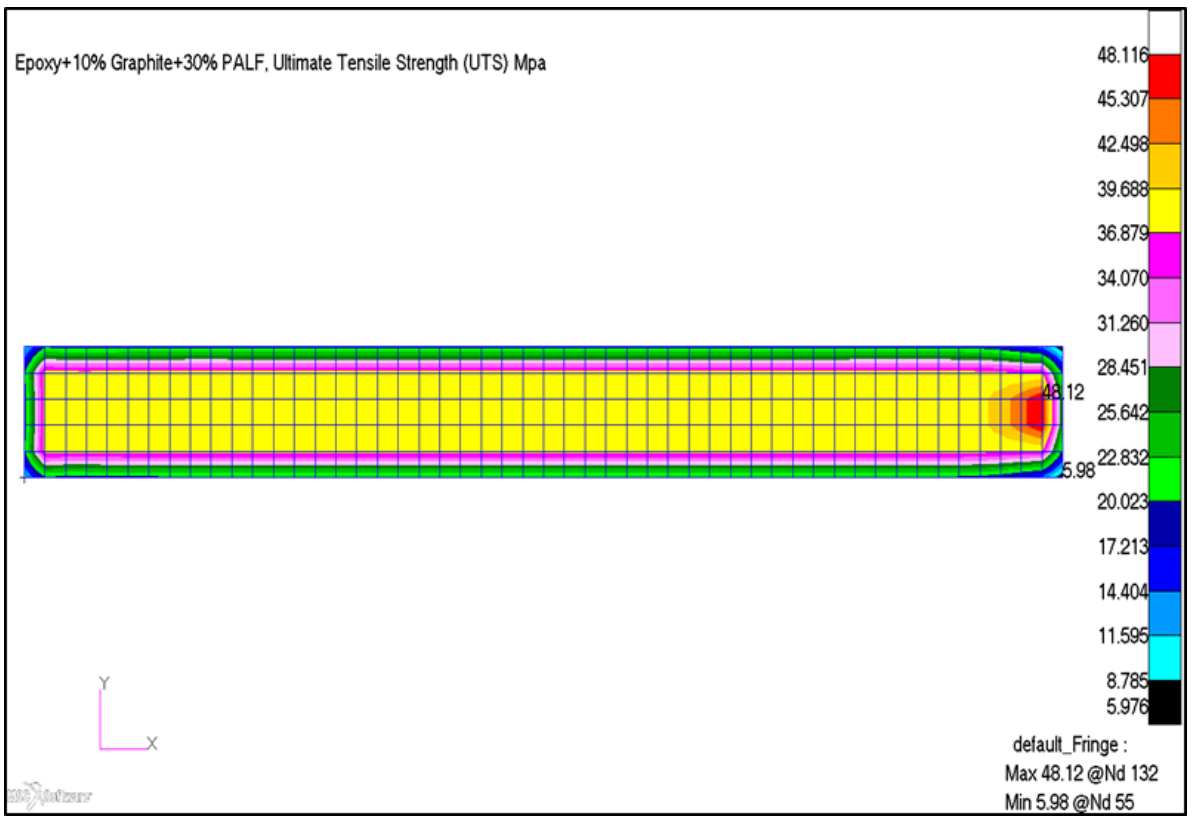

d)

Fig. 6.Tensile strength of (a) Epoxy with 5\% graphite fillers (b) Epoxy with 10\% graphite fillers (c) Epoxy with 5\% graphite-30\% PALF (d) Epoxy with 10\% graphite- 


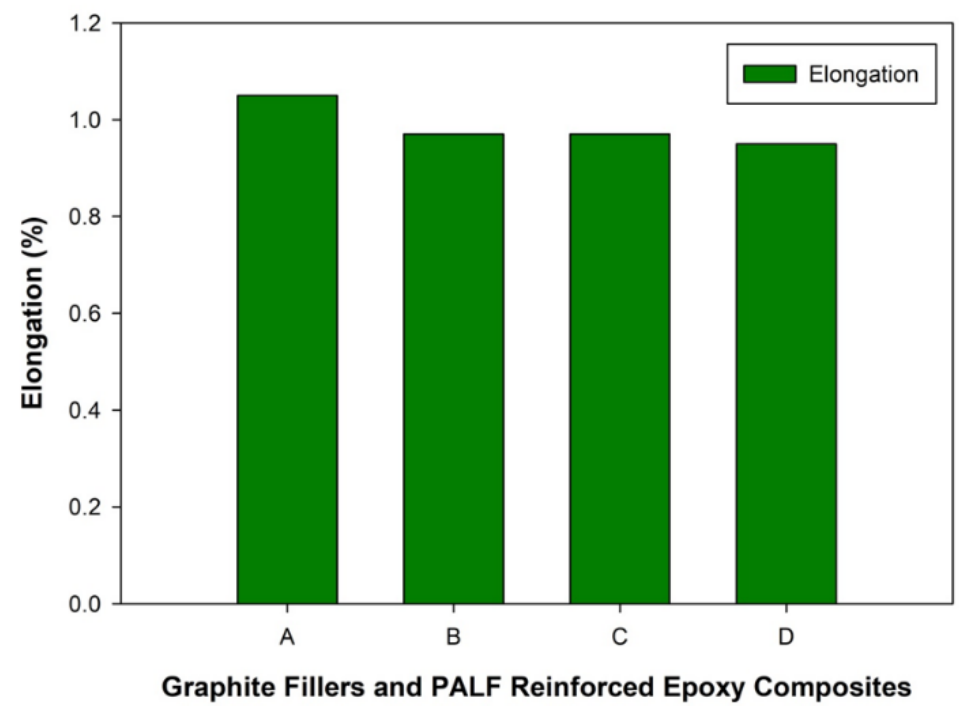

Fig. 7 Percentage elongation of graphite fillers and PALF reinforced epoxy composites.

Percentage elongation of graphite fillers and pineapple leaf fibers reinforced composites are represented in Fig. 7 and Table 2. The ductility of epoxy with 5\% of graphite fillers, $10 \%$ graphite fillers, 5\% graphite-30\% PALF and 10\% grapite-30\% PALF reinforced composites are $1.05 \%, 0.97 \%, 0.97 \%$ and $0.95 \%$ respectively. The addition of graphite fillers and pineapple leaf fibers decreased the ductility of epoxy composites. Further, from plot 7 , as graphite filler contain increased to $10 \%$, there is a decrease in the elongation. This ductility has reduced to $0.95 \%$ with the incorporation of $30 \%$ PALF along with graphite particles filled epoxy composites. Both the PALF and graphite act as a barrier for the deformation during tensile loading. Danladi et al. [29] studied the ductility of pineapple leaf fibers reinforced high density polyethylene composites. As the PALF content increased to 0 to $50 \%$ there was a decrease in the elongation.

\section{Flexural Strength}

Bending test for graphite and PALF reinforced composites is done according to ASTM D790 standard technique using a Universal testing machine (UTM). All the flexural examples are tested at room temperature, a constant strain rate of $5 \mathrm{~mm} / \mathrm{min}$ is used for all samples. Three samples were tested for each of the particular compositions. The 3 Point flexural tests were conducted to evaluate bending strength and rigidness of graphite-PALF composites. Fig. 8 and Table 3 are showing according to the results noted in the 3 point flexural test. The flexural strength of 5\% expanded graphite filled epoxy composites is $137.2 \mathrm{MPa}$. This strength increased as the volume percentage of expanded graphite content increased to $10 \%$.

Further, the flexural strength of the epoxy composites was enhanced with the addition of $30 \%$ PALF in 5 , and $10 \%$ of graphite fillers reinforced composites. The highest flexural strength is observed in 5\% graphite and 30\% PALF fibers reinforced epoxy composites is $171.4 \mathrm{Mpa}$. The improved flexural strength is mainly due to the 
strong adhesion between the epoxy, fillers, and fibers. The flexural strength of jute fibers reinforced epoxy composites with $\mathrm{SiC}$ fillers was studied by Manohar et al. [30] have noticed improved strength due to the combined effect of jute fibers and $\mathrm{SiC}$ particles in the epoxy resin.

Table 4 Flexural properties of epoxy with graphite and PALF compsites

\begin{tabular}{ccc}
\hline Composite Code & Flexural Strength (MPa) (UTM) & Flexural Strength (MPa) (FEM) \\
\hline A & 137.2 & 139.8 \\
B & 148.3 & 152.3 \\
C & 160.4 & 163.2 \\
D & 171.4 & 173.8 \\
\hline
\end{tabular}

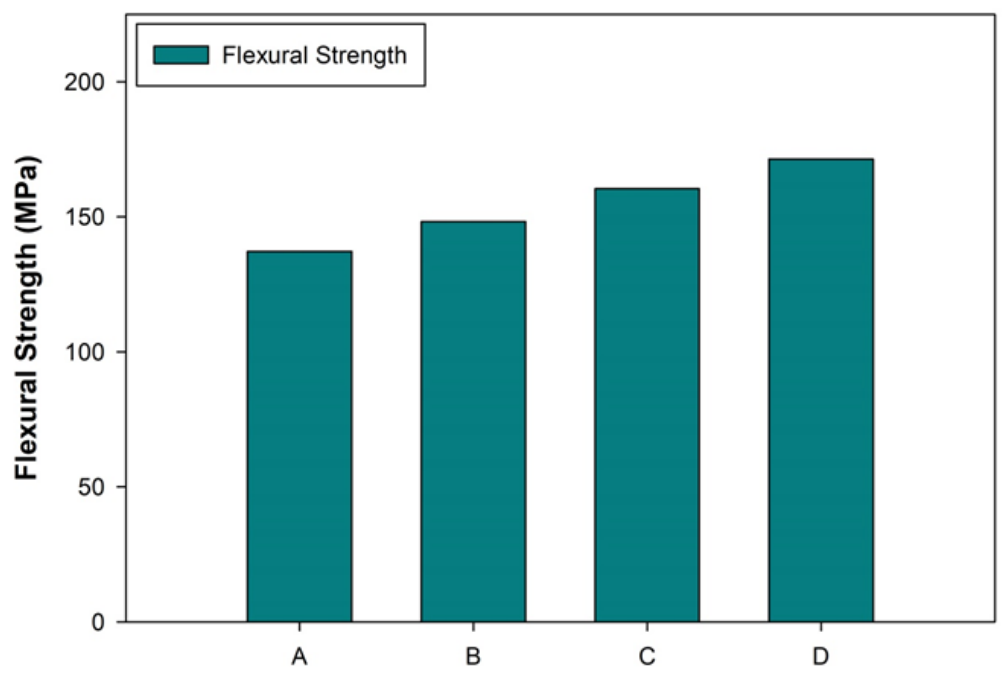

Graphite Fillers and PALF Reinforced Epoxy Composites

Fig. 8 Flexural strength of graphite fillers and PALF reinforced epoxy composites

Fig. 9 (a-d) and Table 4 demonstrate the flexural strength of varying volume fractions of graphite fillers and 30\% PALF reinforced epoxy composites determined by the analysis method. The flexural strength of 5\% graphite fillers reinforced epoxy composites obtained from the FEM method is $139.8 \mathrm{MPa}$, as in Fig. 9(a). Similarly, $10 \%$ graphite fillers reinforced composites $152.3 \mathrm{MPa}$ (Fig. 9b), in the case of 5\% graphite-30\% PALF and 10\% graphite-30\% PALF composites, is $163.2 \mathrm{MPa}$ and 173.8 MPa respectively as in Fig. 9(c-d). The conventional flexural strength test results, as in Fig. 8, are in line with FEM analysis results. 


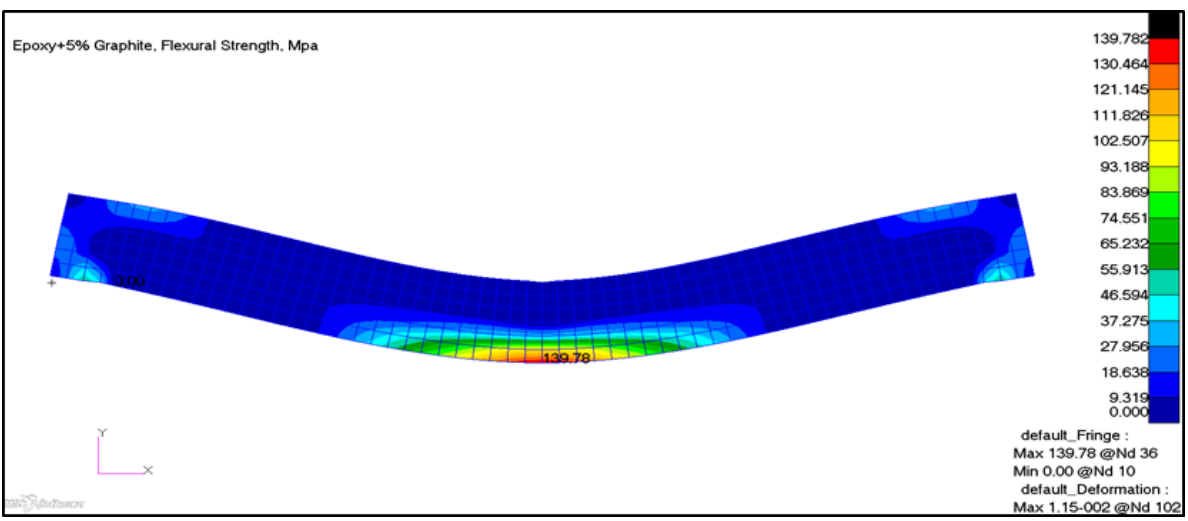

a)

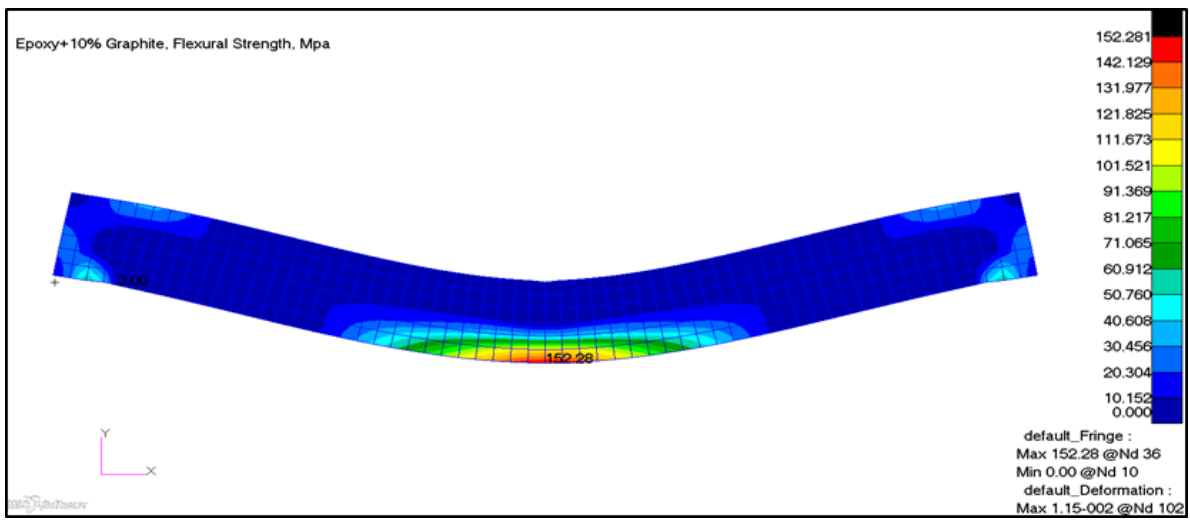

b)

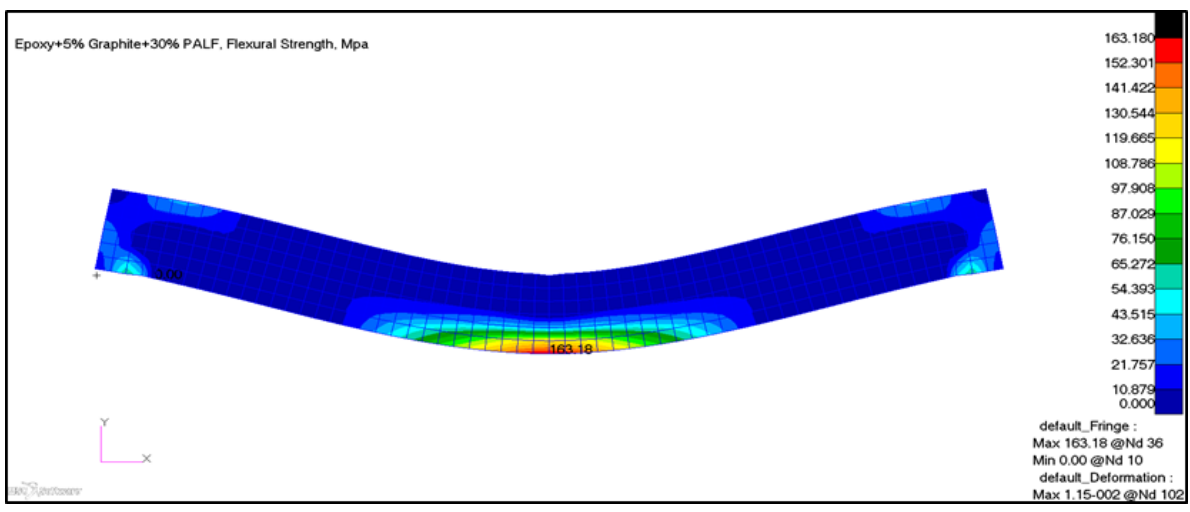

c) 


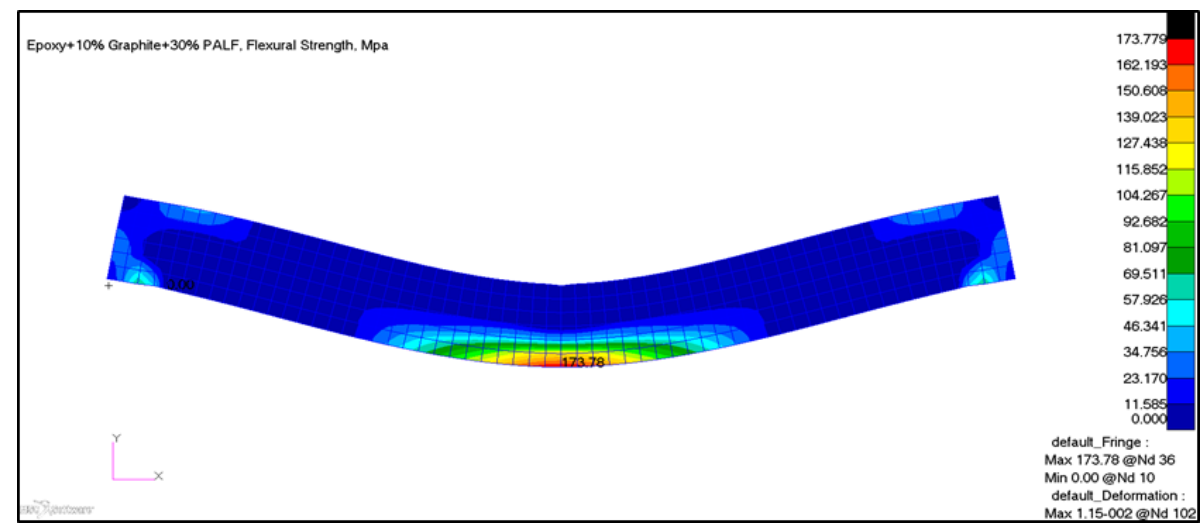

d)

Fig. 9.Flexural strength of (a) Epoxy with 5\% graphite fillers (b) Epoxy with 10\% graphite fillers (c) Epoxy with 5\% graphite-30\% PALF (d) Epoxy with 10\% graphite$30 \%$ PALF composites

Fig. 9 (a-d) demonstrates the flexural strength of epoxy with graphite fillers, and PALF reinforced composites obtained from FEM analysis. The flexural strength of these composites is analyzed with MSC Nastran software. From all the plots, it can be concluded that deformation is minimum in the case of epoxy with $10 \mathrm{wt} . \%$ of graphite and 30 vol.\% of PALF reinforced composites. This enhanced flexural strength is mainly due to the presence of graphite fillers PALF fibers in the epoxy resin.

\section{Conclusions}

In the present study, an effort has been made to understand the flexural and tensile behaviour of hybrid pineapple leaf fiber (PALF) reinforced with epoxy and graphite as filler. FEM simulation was carried out using MSC Patran and Nastran student version. Various composites with 5\% expanded graphite, $10 \%$ expanded graphite, 5\% graphite-30\% PALF, and 10\% graphite-30\% PALF reinforced epoxy composites were prepared by hand layup process. The prepared composites were studied for various mechanical properties like tensile and flexural strength as per ASTM standards. Epoxy composites with 30\% PALF and 10\% expanded graphite filler reinforced composites exhibited superior tensile and flexural properties as compared to remaining composites. Further, there was a slight decrease in the ductility of epoxy with the PALF fibers and graphite fillers. These conventional testing results were validated by using FEM analysis. Both the conventional tensile and flexural strength results were in line with each other. The prepared composites are well suited for automotive and aerospace applications. Especially, these composites can replace high cost carbon fiber reinforced polymer composites in the aerospace applications like air intake duct and fairings of trainer aircrafts. 


\section{References}

[1] Allan C. Manalo, Evans Wani, Noor Azwa Zukarnain, Warna Karunasena: Composites Part B, 80 (2015) 73-83.

[2] Evans A. G, Zok FW: Journal of materials Science, 29 (15) (1994) 3857-96.

[3] Temesgen Batu, Hirpa G. Lemu: Results in Materials, 8 (2020) 100152.

[4] S. Vijayakumar , K. Palanikumar: Journal of Materials Research and Technology, 9 (2020) 7915-7925.

[5] Alfredo R. Sena Netoa, Marco A. M. Araujo, Raiza M.P. Barboza, Alessandra S. Fonsecac, Gustavo H.D. Tonoli, Fernanda V.D. Souza, Luiz H.C. Mattoso, Jose M. Marconcini: Industrial Crops and Products, 64 (2015) 68-78.

[6] Guolong Wanga, Demei Yua, Ajit D. Kelkar, Lifeng Zhang: Progress in Polymer Science, 75 (2017) 73-107.

[7] K. Senthilkumar, N. Saba, M. Chandrasekar, M. Jawaid, N. Rajini, Othman Y. Alothman, Suchart Siengchin: Construction and Building Materials, 195 (2019) 423-431.

[8] Yusri Yusofa, Siti Asia Yahyaa, Anbia Adama: Procedia CIRP, 26 (2015) 756760.

[9] Yadvinder Singh, Jujhar Singh, Shubham Sharma, Thanh-Danh Lam, Duc-Nam Nguyen: Journal of Materials Research and Technology, 9 (6) (2020) 15593 15603.

[10] Jiayi Zhu, Chamil Abeykoon, Nazmul Karim: International Journal of Lightweight Materials and Manufacture, 4 (2021) 370-382.

[11] Gabriel Oliveira Glória, Maria Carolina Andrade Teles, Anna Carolina Cerqueira Neves, Carlos Maurício Fontes Vieira, Felipe Perissé Duarte Lopes, Maycon de Almeida Gomes, Frederico Muylaert Margemc , Sergio Neves Monteiro: Journal of Materials Research and Technology, 6 (4) (2017) 411-416.

[12] S. Sathees Kumar, Ganesan Kanagaraj: Journal of Polymer Engineering, 37 (2017) 547-557.

[13] S. Sathees Kumar, Ganesan Kanagaraj: Arabian Journal for Science and Engineering, 41 (2016) 4347-4357.

[14] S. Sathees Kumar, Ganesan Kanagaraj: Bulletin of Materials Science, 39 (2016) 1467-1481.

[15] S. Sathees Kumar, Ganesan Kanagaraj: Journal of Polymer Analysis and Characterization, 21 (2016) 378-386.

[16] S. Sathees Kumar, Ganesan Kanagaraj: Journal of Inorganic and Organometallic Polymers and Materials, 26 (2016) 788-798.

[17] S.Sathees Kumar: Fibers and Polymers, 21 (7) (2020) 1508-1514.

[18] R.Muthalagu,V. Srinivasan, S. Sathees Kumar, V. Murali Krishna: Fibers and Polymers, 22 (2021) 2018-2026.

[19] V. Mugesh Raja, S. Sathees Kumar: Fibers and Polymers. , (2021) 1-8.

[20] Ajjima Nopparut, Taweechai Amornsakchai: Polymer Testing, 52 (2016) 141149.

[21] Fabio da Costa Garcia Filho, Fernanda Santos da Luz, Michelle Souza Oliveira, Artur Camposo Pereira, Ulisses Oliveira Costa, Sergio Neves Monteiro: Journal of Materials Research and Technology, 9 (3) (2020) 5343-5351.

[22] P.V. Chandrasekhara Rao: Construction and Building Materials, 235 (2020) 117505.

[23] Junpu Wang, Wenzhi Wang, Chao Zhang, Wenshan Yu: Composites Part B, 133 (2018) 185-192. 
[24] Anastasiia Kobyliukh, Karolina Olszowska, Urszula Szeluga, Sławomira Pusz: Advances in Colloid and Interface Science, 285 (2020) 102285.

[25] M. J. M. Ridzuan, M. S. Abdul Majid, A. Khasri, E. H. D. Gan, Z. M. Razlan, S. Syahrullail: Journal of Materials research and Technology, 8 (6) (2019) 53845395.

[26] Tolera A. Negawo, Yusuf Polat, Yasin Akgul, Ali Kilic, M. Jawaid: Composite Structures, 259 (2020) 13221.

[27] Rose Farahiyan Munawar, Nurul Hayati Jamil, Mohd Khairul Shahril, Muhammad Abdul Rahim, Muhammad Zaimi Zainal Abidin, Mohd Asyadi Azam, Kok-Tee Lau: Applied Mechanics and Materials, 761 (2015) 520-525.

[28] Temesgen batu, Hirpa G. Lemu: Results in Materials, 8 (2020) 100152.

[29] A. Danladi, J. Shuaib: American Journal of Materials Science, 4 (3) (2014) 139143.

[30] K. Manohar Reddy, B. Chandra Mohana Reddy: Materials Today Proceedings, 37 (2021) 917-921.

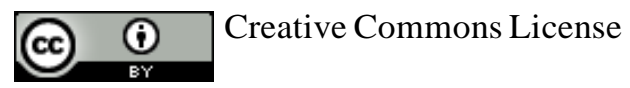

This work is licensed under a Creative Commons Attribution 4.0 International License. 